\title{
Robots and Robotics Kits for Early Childhood and First School Age
}

\author{
https://doi.org/10.3991/ijim.v14i18.16631 \\ Stamatios Papadakis \\ University of Crete, Crete, Greece \\ stpapadakis@gmail.com
}

\begin{abstract}
Educational robotics can consider one of the newest trends in education and they have been introduced into the classrooms ranging from kindergarten through high school as a means of enriching the learning environment and promote knowledge-building activities. Especially, robotics technologies offer opportunities for young age children, for a practical, hands-on understanding of the things they meet in their daily life but do not fully understand, such as proximity sensors, motion detectors, and light sensors, reasoning failures (software bugs) and connection problems (Wi-Fi, Bluetooth disconnection). In this article, we presented robots that can be used in early childhood and first primary classes of education. The purpose of this article is not to advocate against an educational robot or robotic kit but indeed to inform the educational community so that to make informed decisions regarding the introduction of this kind of technology into the classroom.
\end{abstract}

Keywords - Educational Robotics, Robots, Robotics kits, Computational Thinking, Coding, Creativity, Reasoning Thinking, Critical Thinking, Preschool Education, Primary Education

\section{Introduction}

From smart screen technologies to block-based programming environments designed for teaching and learning, digital technologies are introduced in the classroom even from an early age [1] [2]. Over the past decade, a wide range of interactive technologies and tools designed especially for young age children, such as block-based visual programming environments (ScratchJr, Scratch, MIT App Inventor, etc.), and robotics have been introduced into the classrooms [3] [4] as a means to improving teaching, learning [5].

Especially educational robotics can consider one of the newest trends in education and they have been introduced into the classrooms ranging from kindergarten through high school as a means of enriching the learning environment and promote knowledgebuilding activities [6] [7]. Sullivan and Bers state that robotics provides educational opportunities for children to engage with STEM (Science, Technology, Engineering, and Mathematics) subjects and coding activities and engineering concepts since kindergarten [8]. What is also important is that the various elements of robotics kits, such as 
the variety of sensors and interaction possibilities, the possibilities for customization, the neutral gender colors and design in conjunction with children friendly programming environments make robots accessible to all children regardless of gender, ethnicity, race, etc. [9]. This is considered important as due to gender inequalities in access to computational resources, programming environments, and even school textbooks, female students are much less likely to succeed in the informational society and technology-related jobs [10]. On the contrary, research has shown that male students tend to be more familiar with computers and web-based technologies and need a reduced level of cognitive effort to reach a given level of computational accuracy. Besides, the boys are more experienced with computers and their coding and have a more positive attitude toward programming and relative coding activities than their female classmates [11].

In the context of educational robotics (ER) learning activity children construct and program robots employing sensors, motors, etc. through play, group challenges, and hands-on activities [12]. Educational robotics found its roots in both the constructivist and constructionist learning theory [13]. Based on constructivism [14], students work out related concepts of authentic problems in small groups. Students' relating experiences and knowledge are the necessary basis for possible further productive explorations. Based on constructionism [15], students acquire knowledge and skills based on discovery learning. In this way, constructionism as a theory supports student-centered learning environments that promote critical thinking and problem-solving skills. At the same time, it emphasizes discovery learning by associating prior experiences with tangible objects, integrating what they already know, by making connections between old and new information. The main difference between the two learning theories is that constructivism is referring to the mental processes involved in gaining knowledge, constructionism refers to the construction processes by making things that are tangible and sharable [16].

Educational Robotics can be considered as a multidisciplinary approach involving aspects as diverse as design algorithms, design mechanical structures, construction, and operation of robots and robotics kits as well as the possibility of applying engineering mathematics, physics principles, and other science subjects [17]. In general, these characteristics and methods are very well suited for the design of activities with STEM orientation [2]. Educational robotics has many real-world applications in various fields of science, mathematics, and engineering helping to remove the abstractness of these scientific fields while improving skills, and effective learning strategies such as spatial ability, selective attention, risk-taking, decision-making skills, etc. [18]. Especially, robotics technologies offer opportunities for children and young people, for a practical, hands-on understanding of the things they meet in their daily life but do not fully understand, such as proximity sensors, motion detectors and light sensors [19], reasoning failures (software bugs) and connection problems (Wi-Fi, Bluetooth disconnection).

Except for STEM education purposes, robots and robotics kits are an effective way of introducing preschoolers to coding and the development of CT [20] [21] as young children through robotic activities are engaged in the attempt not only to solve some practical problems, but to implement the solutions [19]. Developmentally appropriate robotic activities can offer a 'low floor' (minimal amount of cognitive investment required to start an activity), a 'high ceiling' (not set limits on how far can any idea be 
taken), and 'wide walls' (can be used for a wide variety of learning experiences) to preschoolers. Robots construction and programming requires children to engage in complex problem solving to address issues that are of immediate importance: prioritizing and planning complex tasks and switching mental gears. Several higher-order cognitive functions are involved in these tasks, such as information processing, abstraction, reasoning, decision-making, and problem-solving and evaluating [12]. Additionally, as these tools have a physical artifact makes learning less abstract and more direct, an approach that can be used across all STEM disciplines [22] [23]. Positive changes were found among the children who have participated in various studies with robots as it was found that the children had acquired new knowledge and new skills on developing programming sequences through the use of developmentally appropriate robotics skills, as they were able to check the accuracy of their models and to detect errors in their coding sequences [13].

Educational activities with robots are widespread, considering the diverse options available both in terms of robotics kits and the learning activities designed to assist the learners to accomplish certain specific objectives [24]. In particular, the pedagogical objectives of robotics can be divided into two principal categories: a) handling robots and b) build a robot [23]. Educational robotics in early childhood education is mainly about handling and not building robots and endorses an alternative way of learning programming, through developing initial thinking component that is to move objects in space [24]. In this context we can distinguish two major types of contexts for early childhood and first school age: a) the robotics construction kits (e.g. LEGO®-WeDo, etc.) allows construction and programming of the robot and b) programmable robots (Bee-Bot, etc.) [25].

The scope of the article will be limited to the presentation of robots and robotics kits that can be used at early childhood and first classes of primary education building knowledge and computational thinking skills and are designed to bridging the theorypractice gap. Although several scientific papers describe prototype educational robots and/or robotic kits such as the Dr. Wagon [26], the Curlybot [27], the Electronic blocks [28], the Topodo (https://tangible.media.mit.edu/project/topobo/) or discontinued educational robots such as Parallax Scribbler 2 Robot [9], and social robotic platforms such as DragonBot [29] or child-sized humanoid robots such as KASPAR [30] and NAO [31] it is out of the scope of this paper the presentation of these tools. As such, in this paper, we focus on commercial products that were available on the international online market and can thus be used by early childhood and first school-age students.

\section{Robotics Construction Kit and Logo-Like Programmable Robots}

Robots can be classified as robotics construction kits and programmable robots. According to Komis and Misirli (p.241), a robotics construction kit is an environment in which the robot is made of building blocks, Lego type typically [25]. This category represents the most typical example of educational robotics, as it combines both the 
construction and the programming section of this pedagogical approach. On the contrary, programmable robots are prefabricated floor robots, which are programmed by the user to execute a sequence of commands [32].

\subsection{Robotics construction kit}

KIBO robotics kit: The $\mathrm{KIBO}$ robotics kit from Kinder Lab Robotics (https://kinderlabrobotics.com/kibo/) offers playful experiences for young children while they acquire computational thinking, coding, and engineering skills via the construction and programming of a robotic structure (see Figure 1). Children by using sequences, loops, and variables as well as motors, sensors, and craft materials learn about algorithms, process redesign, modularity, analysis, etc. Unlike other robotics kits that target children at young ages, the KIBO robot doesn't require any screen-based device such as a PC or tablet. Indeed, it is programmed to respond to situations by using tangible programming blocks [19]. KIBO's programming language is composed of 18 commands representing by an equal number of wooden programming blocks that simulate simple motions such as 'move Forward' or more advanced programming concepts such as 'Repeat Loops'.

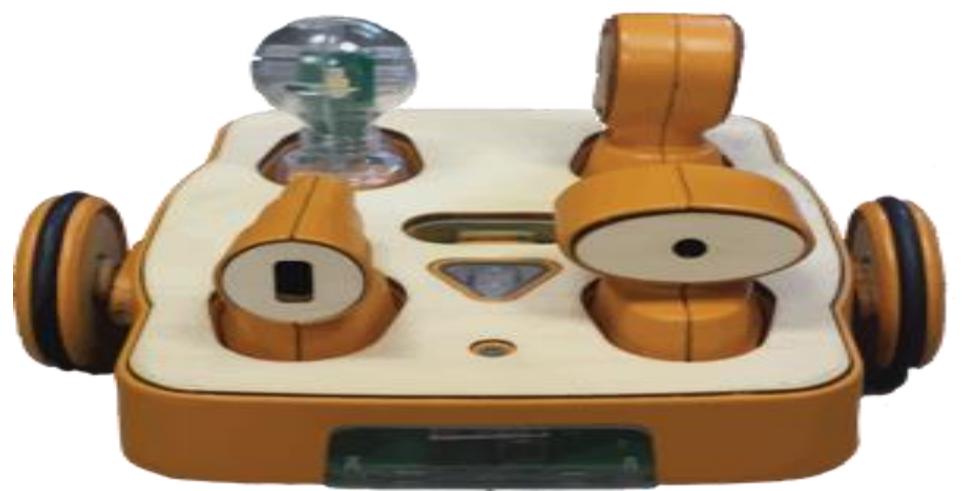

Fig. 1. The KIBO robotics kit

Cubelets: The Cubelets from Modular Robotics (http://www.modrobotics.com/) allow children aged as young as four to familiarize themselves with programming by connecting preprogrammed blocks (see Figure 2). Similar to the KIBO robotics kit the preprogrammed blocks do not need to connect to any screen-based device. The physical blocks can snap together to connect a power source to a sensor and a buzzer or make a light-dependent on a motion sensor or a motor respond to sound. When students need more functionality and mobility, they can graduate from the Cubelets robots to the MOSS robotics kits [33]. 


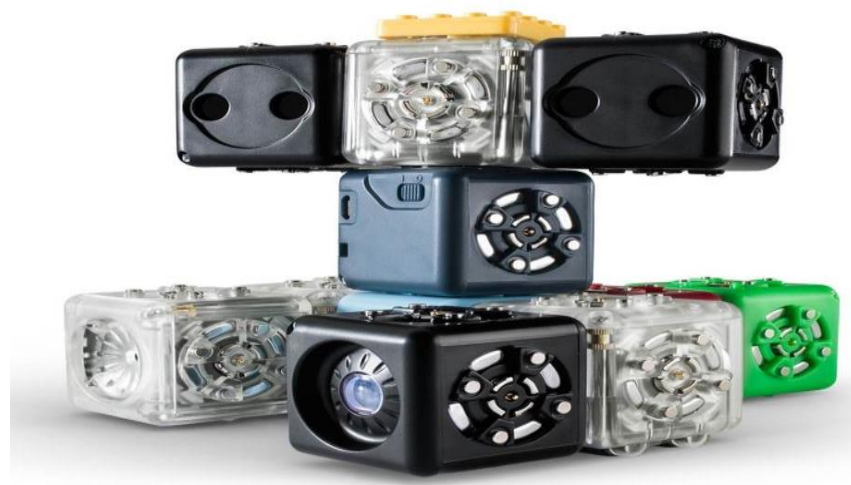

Fig. 2. The Cubelets

Cubetto: Cubetto from Primotoys (https://www.primotoys.com) is another robot tool that it doesn't use any extra connections to screen-based devices (see Figure 3). Cubetto is made of durable wood and thus it is unlikely to be damaged [34]. The Cubetto consists of 4 different parts: 1. Cubetto 2. Programming table, 3. 16 blocks ( 4 forward, 4 right, 4 left, 4 function), and 4 . Cubetto World Map which provides an adventure playground for children. Coding is done by placing blocks in the command lines of the programming table.

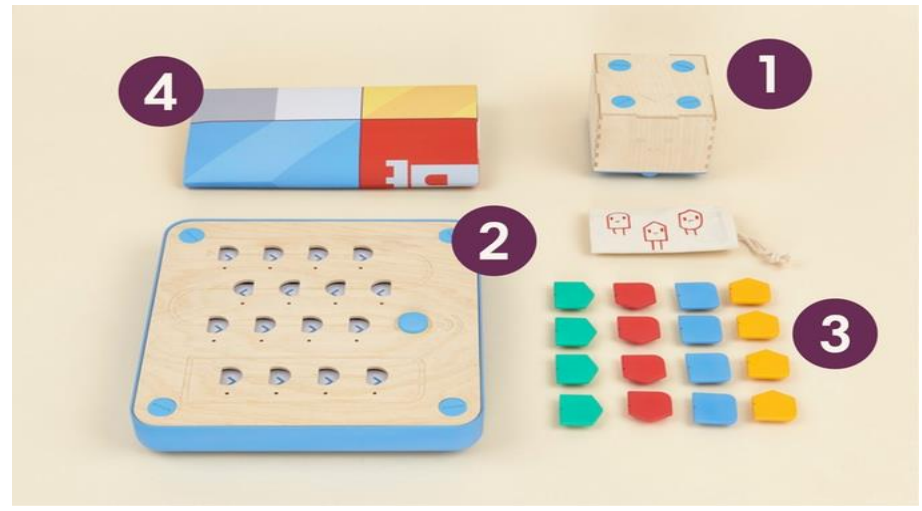

Fig. 3. The Cubetto

LEGO Education WeDo: The LEGO Education WeDo 2.0 from the LEGO Group (https://education.lego.com/) is a robot-based learning system that targets children aged seven and up and it can be considered as a simpler version of the sophisticated version of a Lego Mindstorms robot (see Figure 4). Lego WeDo has a small kit of motors and sensors that allow students to construct programmable LEGO projects. The main control block connects via USB to a computer running either the native Lego WeDo program or Scratch 3.0. The programming platform that ships with WeDo have very little text and can be used by prereading students via a PC or a tablet type device. 


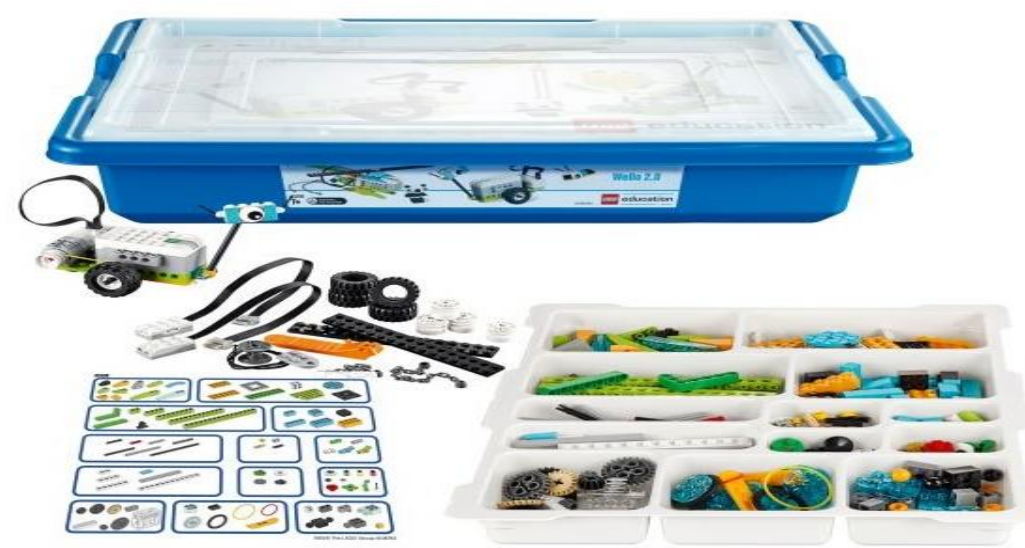

Fig. 4. The LEGO Education WeDo 2.0

Edison robot: The Edison robot from Meet Edison (https://meetedison.com/) besides its low cost it is easily expandable using LEGO bricks (see Figure 5). Using preprogrammed series of activities, children as young as four can learn the fundamentals of computational thinking and coding as well as necessary skills such as critical thinking, decision making, etc. The Edison robot comes with 2 IR LEDs and one IR receiver module. Edison can be programmed from a computer or tablet using various programming languages based on Scratch and Python make it compatible for older students.

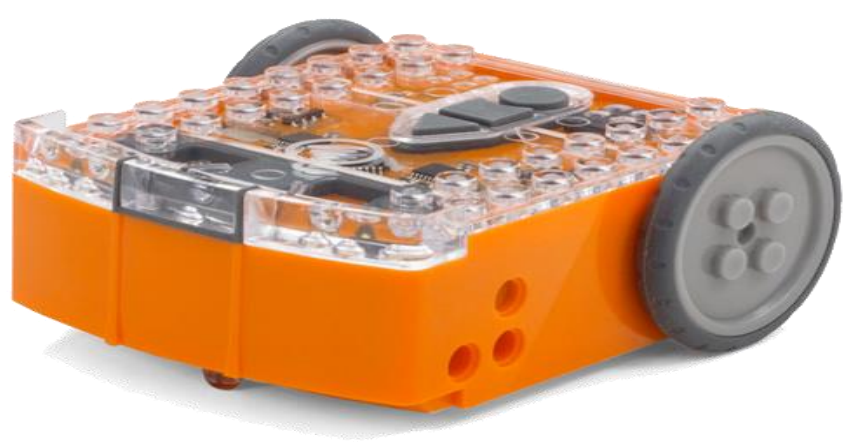

Fig. 5. The Edison robot

MeeperBOT: The meeperBOT from Meeper Technology (https://meeperbot.com/) is a studded platform that is powered by two motors and controlled by a mobile app available for Apple or Android mobile devices (see Figure 6). The children after a brickblock creation with Lego, Mega Bloks, and/or other compatible bricks they can program it to move forward, backward, left, and right. 


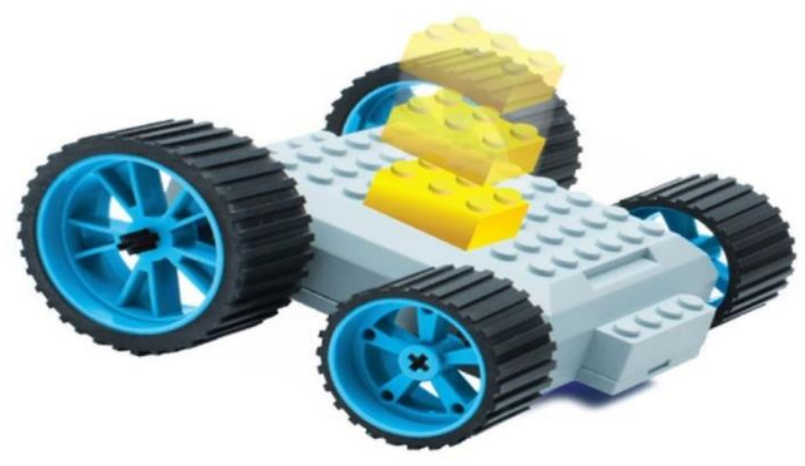

Fig. 6. The meeperBOT

COJI: The COJI from WOWWEE (https://wowwee.com/coji) is a wheeled robot with an LCD monitor, command buttons, LED, and speaker devices. An app for coding the robot that mainly includes motion command and emojis blocks (see Figure 7). The COJI can be controlled using a free app available on iTunes or the Google Play store for compatible smart devices featuring Bluetooth Smart technology. According to the WOWWEE company, the app features six fun and exciting modes that will teach the child to use the building blocks of coding, including commands, loops, sequences, and macros by using a language they already know - EMOJIS.

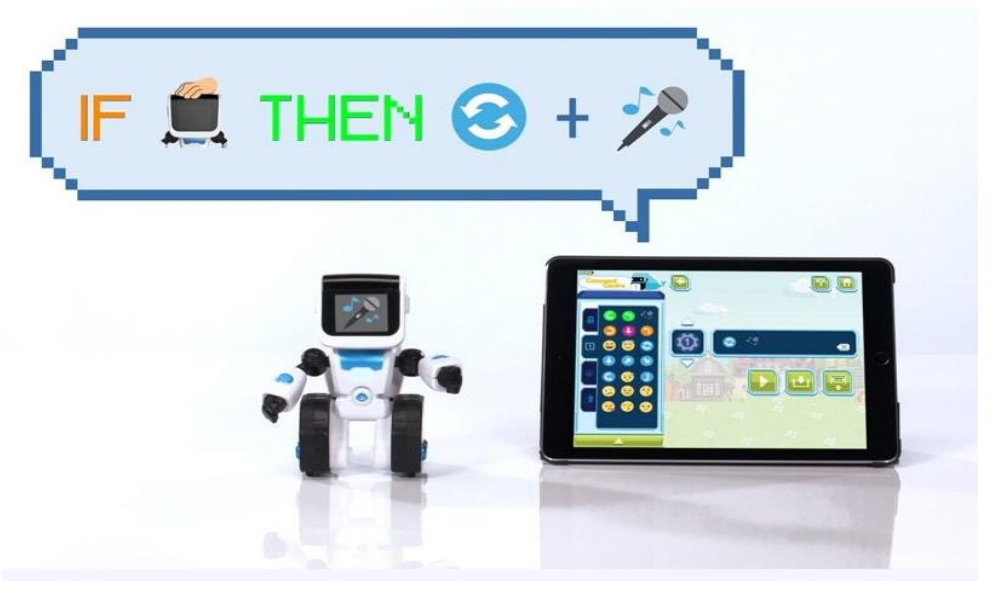

Fig. 7. The COJI

Sphero mini: The Sphero Mini robot from Sphero (https://sphero.com/collections/for-school/products/sphero-mini) is a tiny programmable robot the size of a ping pong ball equipped with a gyroscope, accelerometer, and colorful LED lights (see Figure 8). The robot comes with 3 Mini Traffic Cones and 6 Mini Bowling Pins to inspire children to engage with obstacle courses. The children can use the blocks drive mode to code the robot with basic drag and drop commands with the Sphero Edu app. The 
Sphero Edu app is compatible with smart mobile devices with iOS and Android OS as well as with PCs with macOS and Windows.

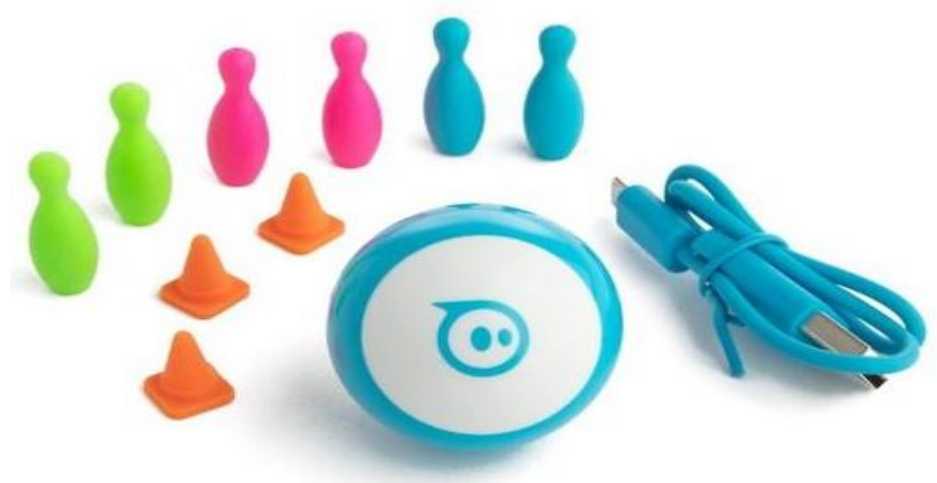

Fig. 8. The Sphero Mini robot

Max \& Tobo coding robot: The Max \& Tobo Coding robot by Tutobo (https://www.tutobo.com/) is featuring a programmable robot that tries to help young age children to learn coding by playing an intergalactic story (see Figure 9). The children by using a mobile app (available for Android and iOS-based devices) program the robot with the Blockly language. The robot comes with an interactive game board. Interacting with the board, the children must complete a story comprising ten levels.

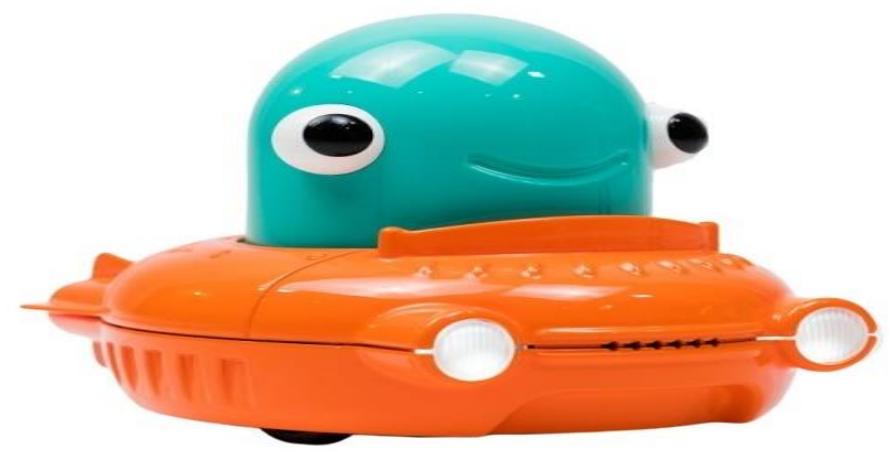

Fig. 9. The Max \& Tobo Coding robot

Robo Wunderkind: The Robo Wunderkind from Robo Technologies (https://robowunderkind.com/) is a robotics kit that allows children to build functioning, programmable robots with interchangeable parts, commanded by a Robo app (see Figure 10) available for smart mobile devices with iOS and Android Operating System. The colorful "smart cubes" embed gadgets as varied as cameras, proximity sensors and laser pointers. 


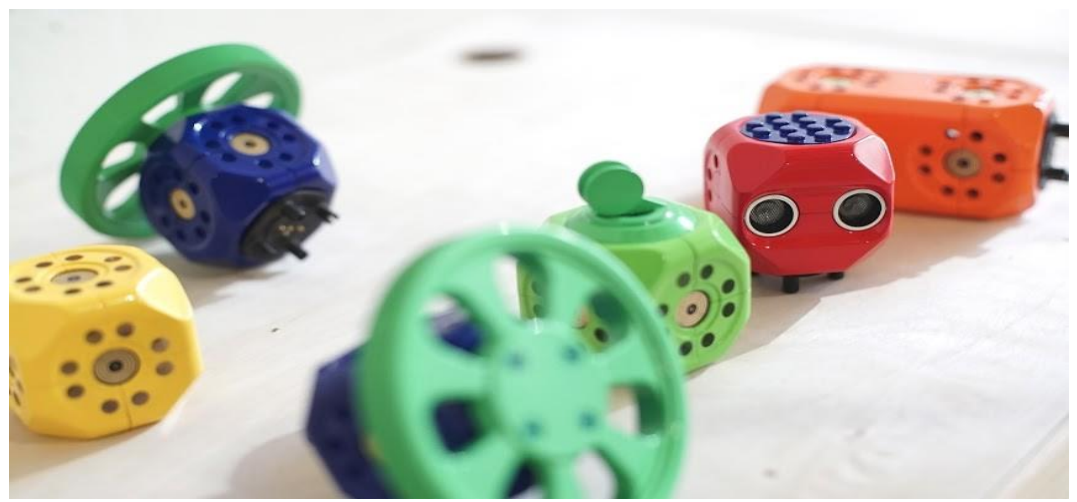

Fig. 10. Robo Wunderkind

\subsection{Programmable robots Logo-like environments}

Dash \& Dot: The Dash \& Dot from Wonder Workshop (https://www.makewonder.com/) is a small mobile robot that moves around, make noise, and shin lights (see Figure 11). Dot is its sidekick. Both robots are full of characters and respond to voice commands or app-based commands from a smart mobile device [35]. It includes three microphones, a gyroscope, four infrared transmitters, and two receivers, three range distance sensors, and LEDs.

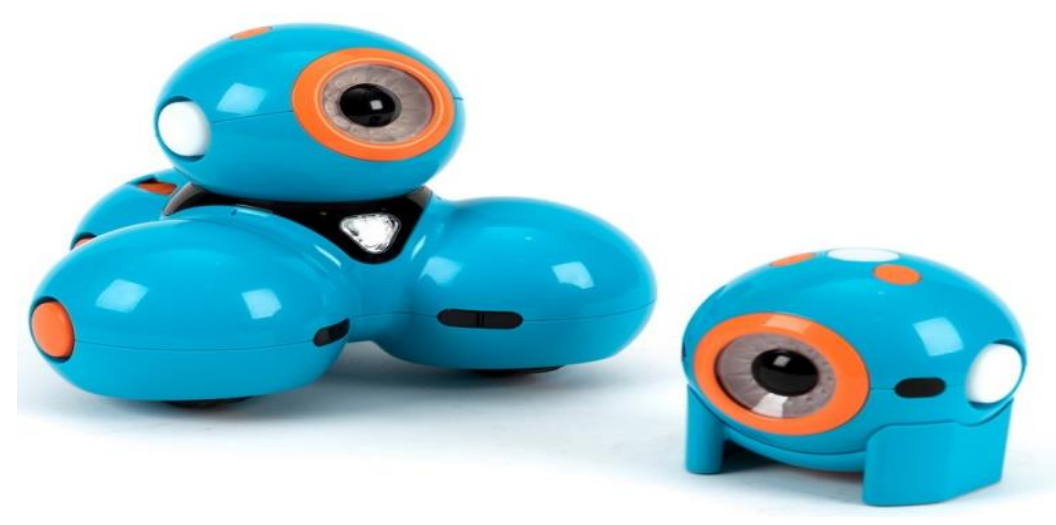

Fig. 11. The Dash \& Dot robot

Bee-Bot / BlueBot: The Bee-Bot Programmable floor robot from TTS Group (www.bee-bot.us) is a bee shape child-friendly robot, while its features such as sounds, and lights make it attractive for use in children (see Figure 12) [36]. Also, the use of buttons on its back makes its use in practice quite easy. The robot supports up to 40 instructions in a single program (in its memory): advance, reverse, turn left $\left(90^{\circ}\right)$ or right $\left(90^{\circ}\right)$, start to move, etc. [13]. At the end of the coding process, Bee-Bot provides in terms of visuals and acoustics cues [12]. 


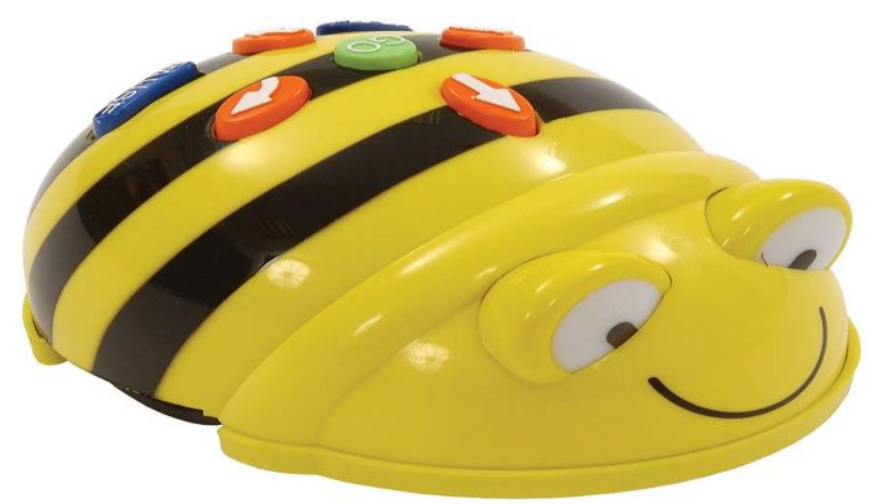

Fig. 12. The Bee-Bot Programmable floor robot

The Blue-Bot is the new Bee-Bot robot with many features such as repeating command sequences and 45-degree turns (see Figure 13). It can be programmed similar to Bee-Bot, but it also can be connected to a tablet or PC via Bluetooth. Thus, a child by using free apps can program Blue-Bot remotely. It is also literally transparent so that its components can be seen, helping to demystify technology.

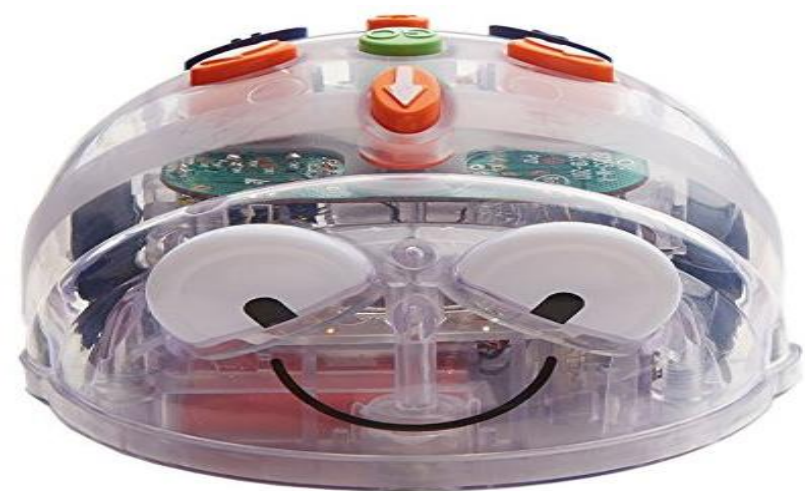

Fig. 13. The Blue-Bot Programmable floor robot

Colby robotic mouse: The Colby from Génération Robots (https://www.generationrobots.com/blog/en/tutorial-robot-mouse-colby/) is a mouse-like educational floor robot, that helps children develop their reasoning and problem-solving skills in a fun and engaging way (see Figure 14). In technical terms, it can be considered functionally equivalent to other programmable robots such as the BeeBot. Similar to BeeBot, Colby provides audio clues, turn on its light and it has 2 speeds as well as colored buttons on the back to program it. It comes also with an activity set that has square shapes and accessories to create a maze, activity cards, command cards, and a magnetic cheese block. 


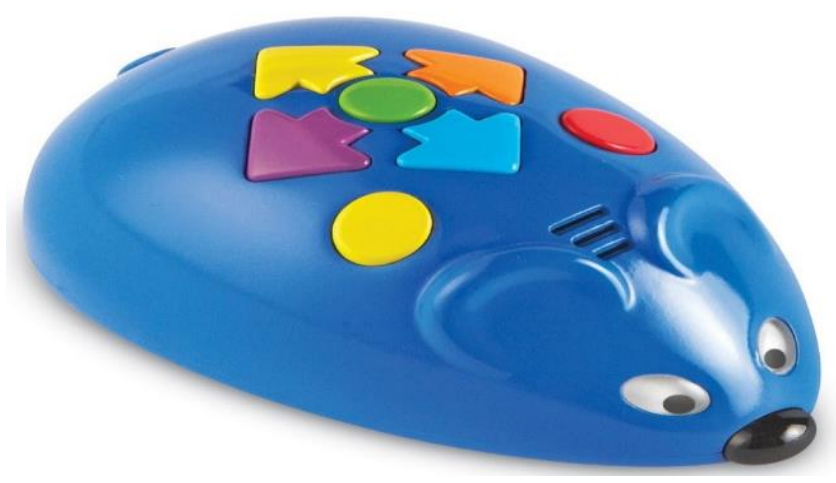

Fig. 14. The Colby robotic mouse

Finch: The Finch from BirdBrain Technologies (https://store.birdbraintechnologies.com/products/finch-robot) is a robot that supports a range of programming environments, providing coding options for students and ages 5 and up (see Figure 15). The Finch responds to light, temperature, and obstacles as it includes light, temperature, and obstacle sensors, accelerometers, among other capabilities.

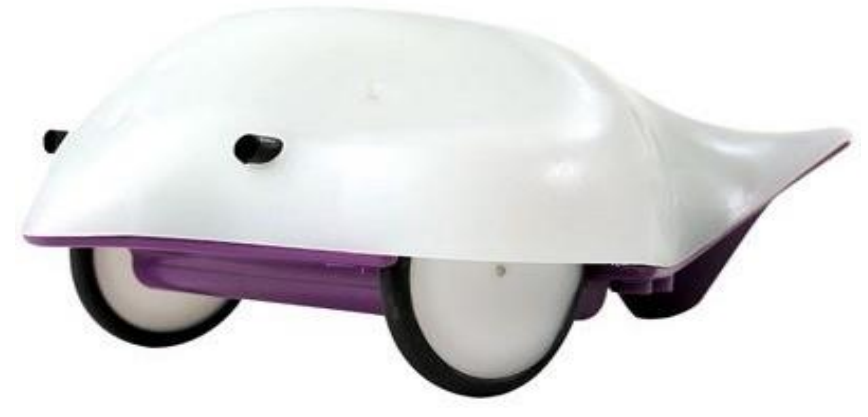

Fig. 15. The Finch robot

Pro-Bot: The Pro-Bot from TTS Group (https://www.tts-international.com/pro-botrechargeable-floor-robot/1009825.html) is another turtle type robot, in the form of a race car (see Figure 16). Similar to Bee-Bot, the commands are entered via a set of arrows and a numeric keypad mounted on its back. Pro-Bot is a most sophisticated turtle type robot that can operate in two modes: a) in a Bee-Bot mode using only the arrow keys and GO button and b) in a Logo mode using arrow keys that can be combined with the number buttons. An extra advantage of Pro-Bot compared to similar type devices like the Bee-Bot is that it can hold a felt-tip pen in its built-in mechanism, allowing it to draw as it moves, much like the Logo turtle on the screen. 


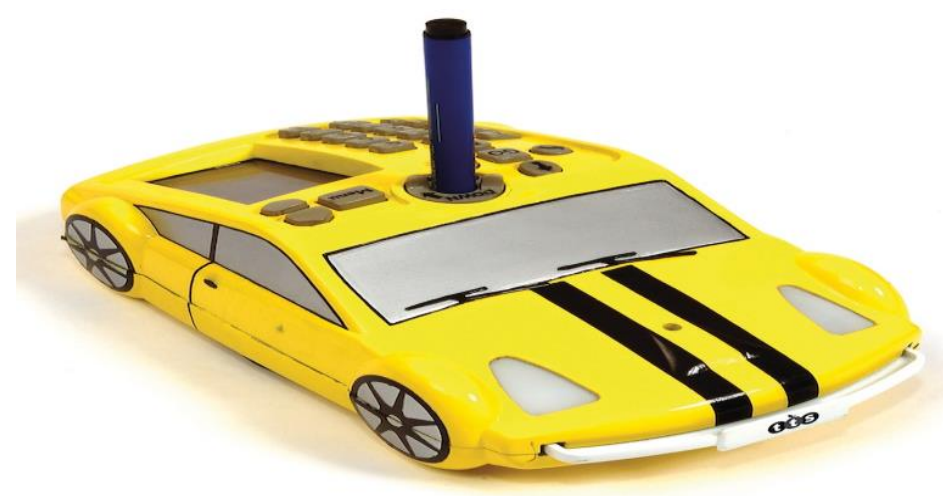

Fig. 16. The Pro-Bot robot

Thymio: The Thymio robot from MOBOTS group (https://www.thymio.org/) is a little white box with wheels (see Figure 17). This neutral look makes it attractive for all the students, regardless of their age and gender. The robot is 'LEGO-compatible' allowing the construction of extension with LEGO bricks to be added to the original work. It also has a relatively large number of sensors and actuators for the successful implementation of advanced projects such as nine IR proximity sensors, an accelerometer, microphone, temperature sensor, remote control receiver, SD-card slot, five capacitive buttons, two motors, a loudspeaker, and 39 LEDs. The Thymio comes with a set of pre-programmed behaviors but it can be also programmed via various programming environments such as Scratch, Blockly and Aseba for Windows and Mac software via the Thymio Suite [9] [37] [38].

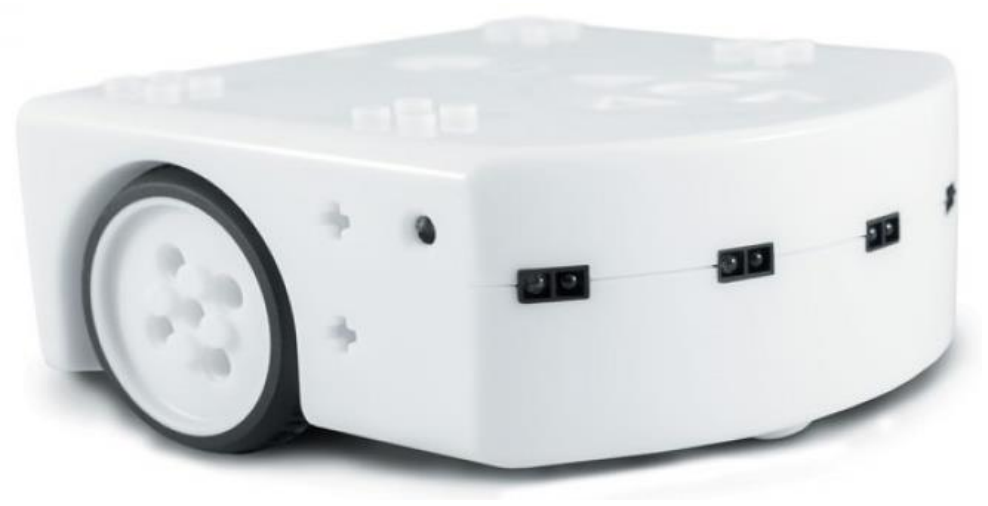

Fig. 17. The Thymio robot

Botley: The Botley toy robot from Learning Resources (https://www.learningresources.com/shop/collections/botley), belongs to the category of non-connected, and thus screen-free smart toys (see Figure 18). Its programming happens with the help of a remote controller provided with the robot toy character [39]. The toy robot beside the basic coding sequences such as Forward, Loop, Right $\left(45^{\circ}\right)$, Left $\left(45^{\circ}\right)$, support also 
advanced coding concepts such as If/Then logic and loop. It also can be programmed for object detection, to toggle between 3 sound settings, among others.

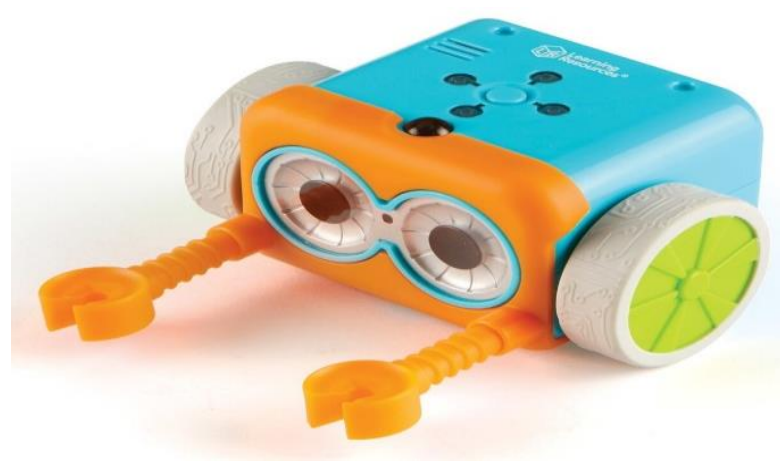

Fig. 18. The Botley robot.

Roamer: The roamer robot from Valiant Technology (http://www.roamer-educational-robot.com/) is not simply another educational robot aimed at helping teach Preschool to Year 12 as it provides increased flexibility because it is a modular system that a child can put together in different ways to suit his/her specific needs (see Figure 19). Its "shell" can be removed and customized, in effect acting as a "disguise" or Carnival costume. The first appearance of a Roamer robot in various schools around the globe has occurred in the early 90s [40]. The programming is performed on the robot itself, with no need for external computer connections, by using the several Logo-like Language commands (forward, back, right, and left) and settings buttons available [41]. The Early Years Roamer uses a counting paradigm to Move, Turn and Wait. The Roamers use numbers to tell the Roamer how far to Move, Turn, or Wait.

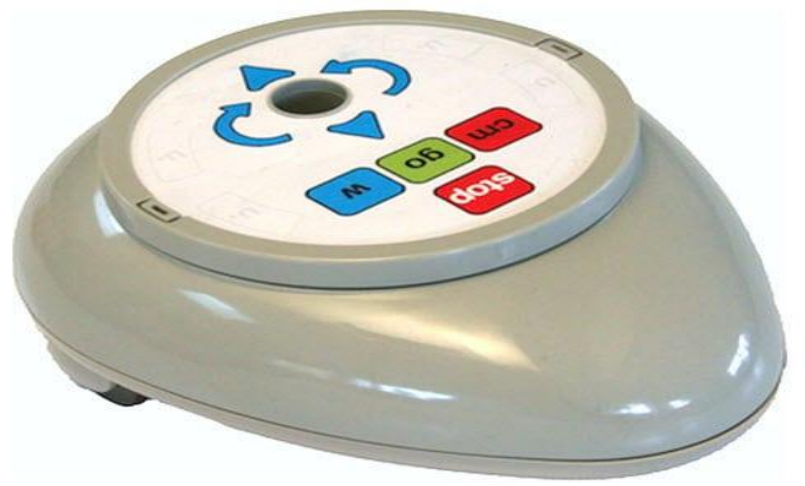

Fig. 19. The roamer robot

Code-a-Pillar: The Fisher-Price Think \& Learn Code-a-Pillar Toy from FisherPrice (https://www.fisher-price.com/en-us/product/think-learn-code-a-pillar-twistgfp25) is a hands-on robotic caterpillar. The children by using the straight left and right 
segments, can arrange Code-a-Pillar segments and watch the caterpillar move accordingly while they can even add lights and sound effects [42] (see Figure 20). According to the Fisher-Price, the robot supports more than 1,000 possible coding combinations and it consists of 1 motorized head and 8 easy-to-connect segments for various combinations.

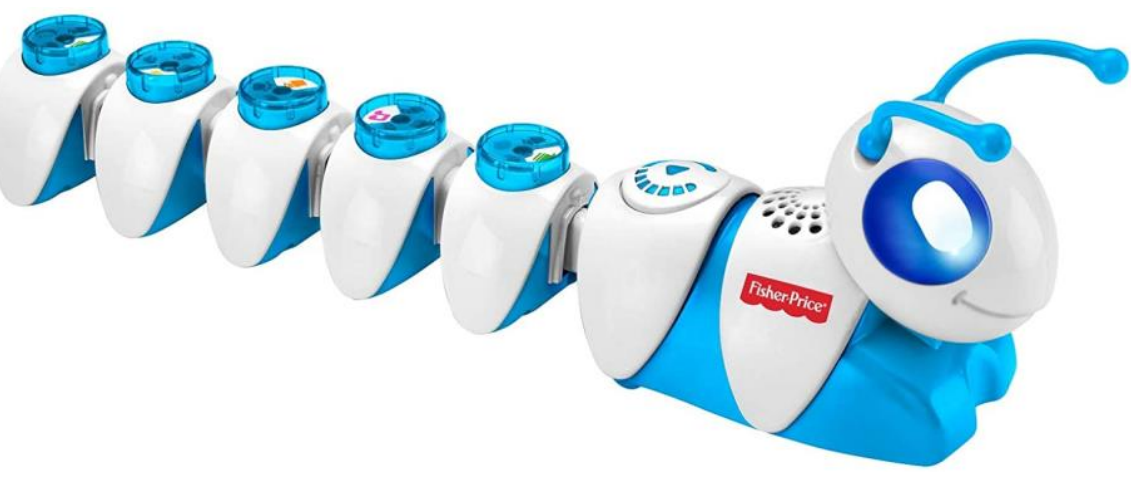

Fig. 20. The Fisher-Price Think \& Learn Code-a-Pillar Toy

Osmo Coding Awbie: The Osmo Coding Awbie from TIDAL Lab at Northwestern University (https://www.playosmo.com/en/coding/) is considered as a hybrid toy that combines 19 Osmo Coding blocks (magnetic) including Walk, jump, grab, loop, if, wonder, multipliers, etc. and 1 game app (see Figure 21). Unfortunately, the coding Awbie app is compatible only with Apple iPad devices (iOS). The children by using the coding commands, control Awbie, a playful character who loves delicious strawberries through a 2-dimensional world filled with strawberries and paths [43].

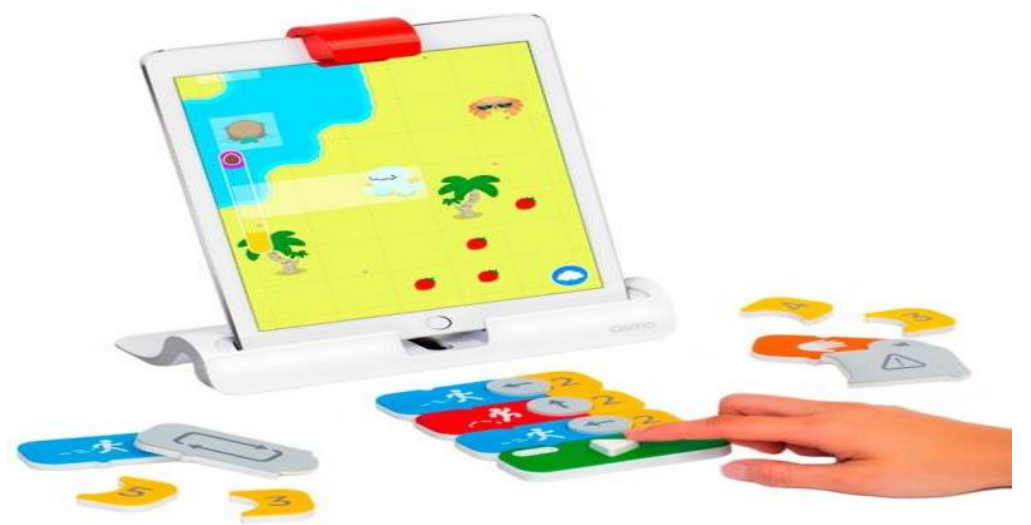

Fig. 21. The Osmo Coding Awbie

Plobot: The Plobot robot created by NYU robotics professor Rudi Cossovich and ex-Google engineer Sean Purser-Haskell, (http://plobot.com/) is an educational robot 
that teaches young learners coding concepts without any need for computer screens (see Figure 22). The robot can move, sing, dance, and entertain while the children learn about algorithms, loops, and conditionals. The children program the robot by tapping or swiping command cards (that represent a block of code) on Plobot's head to string them together and create a 'program' the robot follows - with the "play" card as an executive function [44].

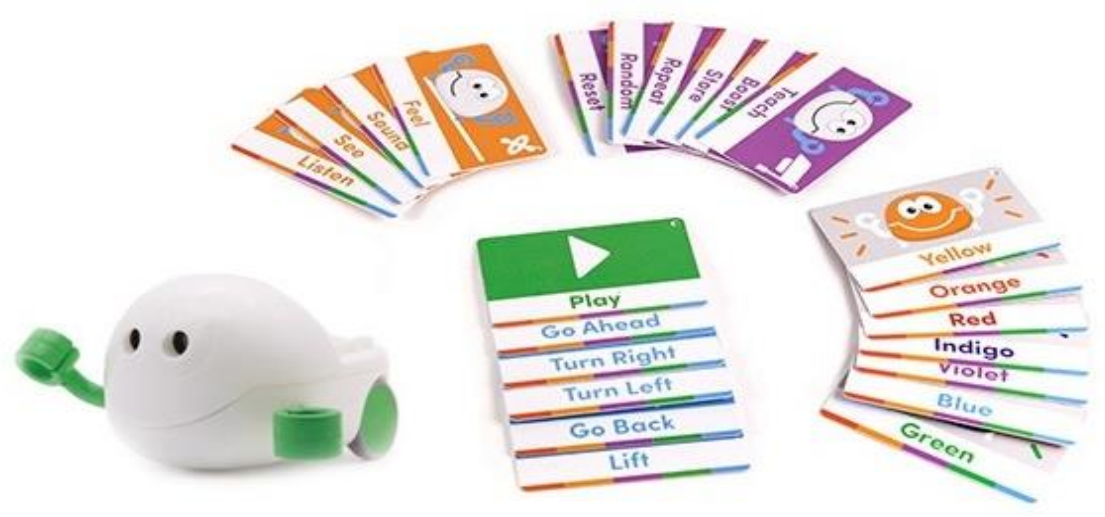

Fig. 22. The Plobot robot

mTiny: The mTiny from Makeblock (https://www.makeblock.com/mtiny) is an education robot for children ages 4 and up (see Figure 23). The mTiny robot comes with a tap pen controller and an interactive map, two characteristics that distinguish it from other products. According to the Makeblock company the children through playful materials including themed maps, coding cards, and a storybook, can develop their computational thinking skills either by completing the tasks assigned on the storybook or by playing freely to discover different solutions. The robot has a screen-free operation meaning that there is no need for the children to use smart mobile devices or PCs.

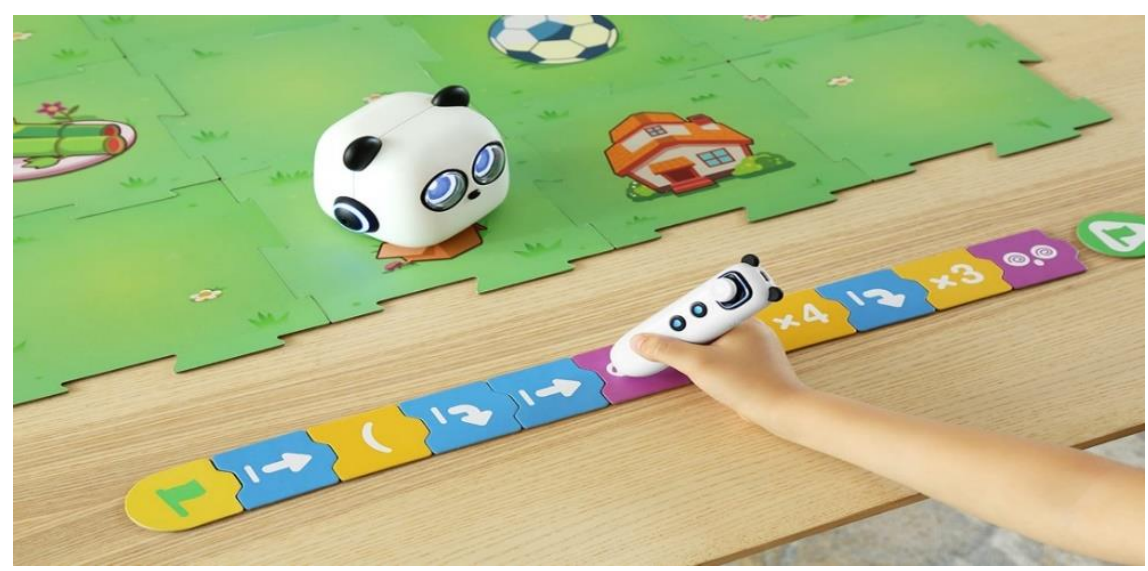

Fig. 23. The mTiny robot 
Mind designer robot: The Mind Designer Robot from Clementoni (https://www.clementoni.com/) is a robot in the form of a car that the children can program either by pressing a series of buttons on its back or, by talking to it thanks to its embedded voice recognition (see Figure 24). The children can also load the bug-looking robot with a coloring pen to draw a picture. It comes also with a free app so that children can experiment with more advanced coding instruction blocks and create complex geometrical shapes.

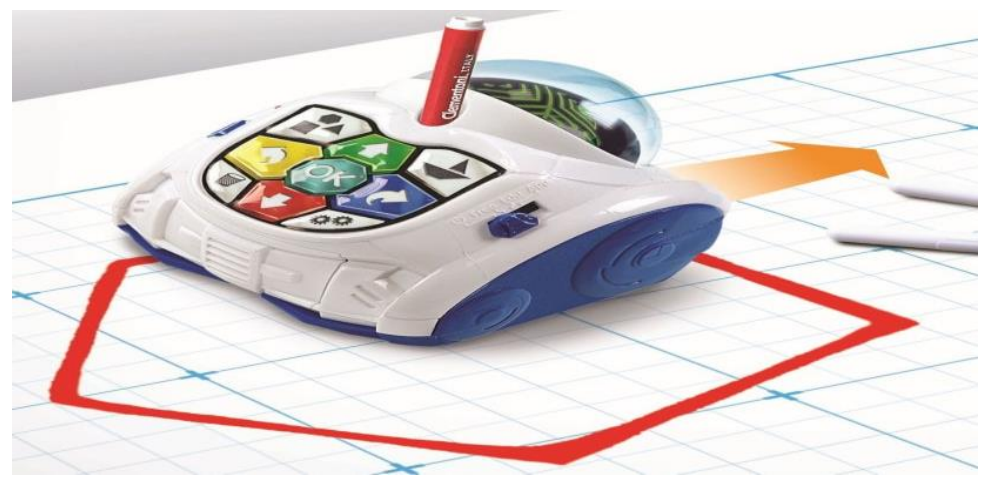

Fig. 24. The Mind Designer Robot

KUBO robot: The KUBO robot from KUBO Robotics (https://kubo.education/) is another screen-free coding solution for the first grades of Primary Education designed to teach young age students various subjects such as coding, language, and music through a tangible coding language; the TagTiles [45] (see Figure 25). The children have to use the Route TagTiles to lay down a route for KUBO to follow or create a function with the Function Tiles.

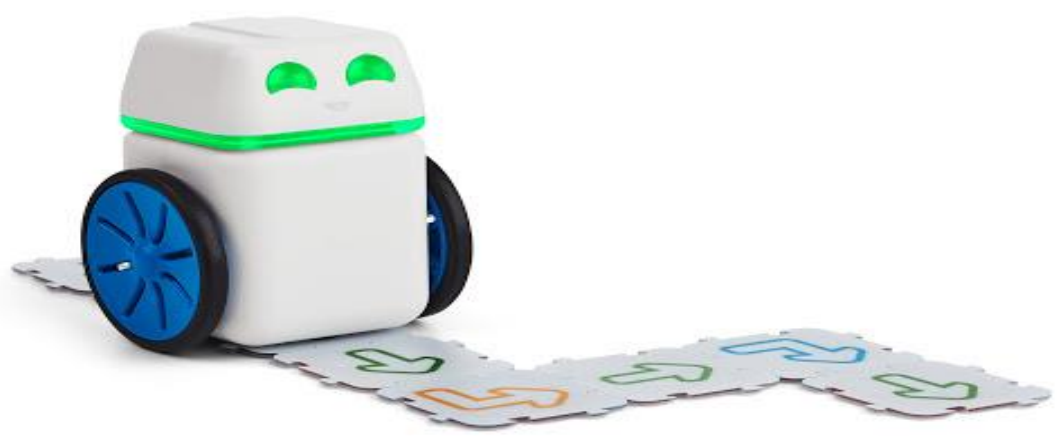

Fig. 25. The KUBO Robot

Evo - Bit: The Evo and Bit from Ozobot (https://ozobot.com/) are two educational robots for children ages five and up including proximity sensors for tricks and obstacle detection, optical sensors for detecting lines and color codes, LED lights and built-in 
speakers (see Figure 26). Both robots come with 2 ways to code-screen-free with Color Codes and on-screen with OzoBlockly (a programming language based on Google's Blockly programming language) via Evo App. Evo is a Bluetooth-enabled Ozobot while Bit is not Bluetooth-enabled. Programming Ozobots Evo and Bit with color codes mean that the robot uses sensors to follow lines and read color codes that the children make with markers or stickers. The Evo App is compatible with most iOS and Android devices.
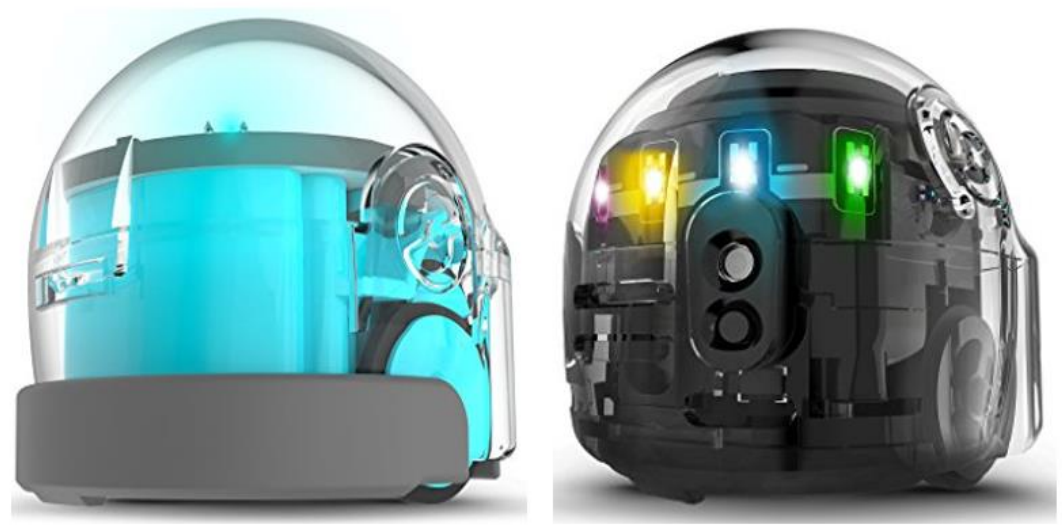

Fig. 26. Evo and Bit robots (Left: Bit, Right: EVO)

Tinkerbots: The Tinkerbots from Tinker Bots (https://www.tinkerbots.de/) is a robotic building set for children ages 5 and up. The children by using easy-to-add robotics can create an endless number of toy robots simply by snapping together Tinkerbots' patented Powerbrain, kinetic modules and passive pieces, and even bricks of other building sets (see Figure 27). No wiring or programming required. It is also app controlled by using an app for Android or iOS smart mobile devices as a remote control.

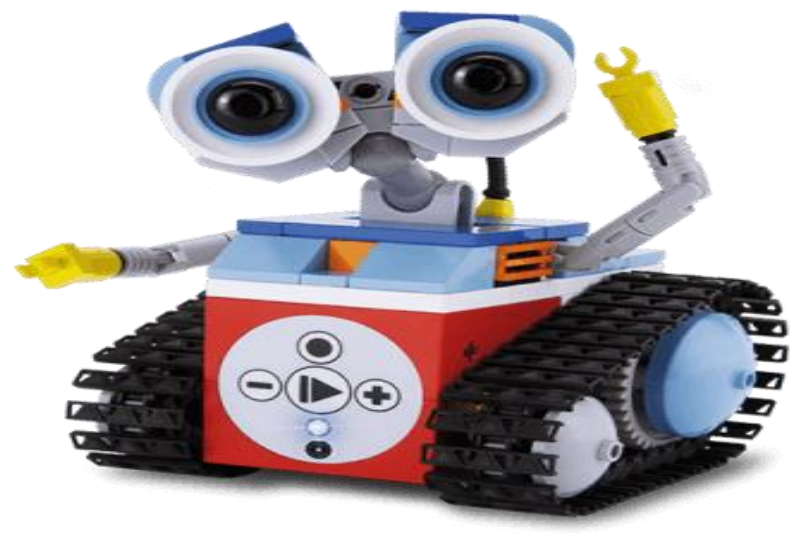

Fig. 27. Tinkerbots robotic building kit 
Matatalab Coding Set: The Matatalab Coding Set from Matatalab (https://matatalab.com/) is a block-based, screenless and tangible programming tool for kids aged 4 and up (see Figure 28). The Matatalab Coding Set allows children to move a robot through a nature map by way of a Bluetooth-enabled command tower and board. The Coding Set includes a Bluetooth-enabled command tower, control board, wheeled robot, and thirty-seven coding blocks in the form of enumerated tiles.

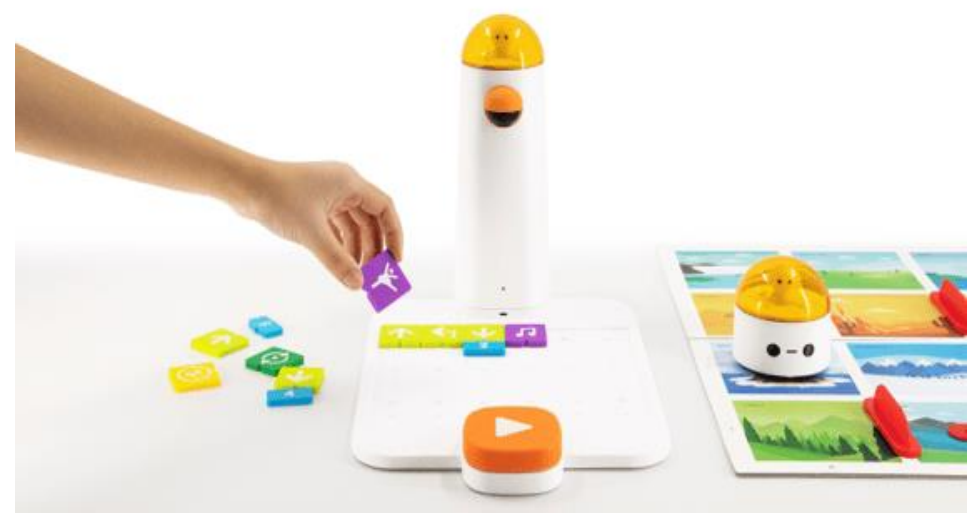

Fig. 28. The Matatalab Coding Set

\section{Drawbacks of the Study}

The main drawbacks of the study that lessen its overall impact are that this work did not follow a systematic mapping guideline, such as the PRISMA method (Preferred Reporting Items for Systematic Review and Meta-analysis Protocols) [46]. Indeed, this study used only the Google Scholar database using the terms 'Educational robots' OR 'Educational Robotics kits' and 'early childhood' or 'First school-age children' following the snowball' 'backward' and 'forward' searches to improve the completeness of the study. Besides, other sources such as websites, workshops, etc. and other 'grey literature' were also included in this study. Finally, it is important to note that the analysis reported in this paper was done only by one reviewer -the author.

\section{Conclusion - Discussion}

In his pioneering work, Seymourt Papert showed that young children can acquire new knowledge, skills and learn by doing, by using the LOGO programming language to guide a "turtle" robot while they foster engagement and enjoyment of learning [15]. After three decades of research, it is widely recognized that the educational robots provide a gateway for young age students to experience the opportunity to engage in educational activities that promote both coding and non-coding approaches [16]. Due to technological advancements, the last decade the robots that can be used in educational 
activities in kindergarten and primary school have been increased dramatically [2]. Educational robotics is a pedagogical approach for developing students' cognitive and social skills attracting the students' interests toward the topic [17]. In an educational robotics environment, children can practice and develop models of cognitive processes that foster creative thinking, effective teamwork, social communication among others [34].

But the introduction of robots in early childhood education settings is a complicated task as it involves both the technical requirements and the school environment [9]. To make learning fun for younger children educators must design techniques and approaches to make robotics appealing to preschoolers [47-48]. For teachers, the success of adopting an educational robotics pedagogy depends on many factors such as the availability of robots and the proper training. Thus, there is an urgent need for quality training programs for the teaching faculty to acquire the necessary skills to bring pedagogy, play, and fun into interaction with one another based on the key ideas of early childhood education [49-50]. Besides, the development of educational material by educational institutions and other organizations will reduce teachers' substantial cognitive load [51-53].

In this article, we presented only robots and robotic kits that can be used at early childhood and first primary classes of education aimed at building knowledge and competencies development of computational thinking and robotics. The interested readers can refer to the relevant literature, including the study of $\mathrm{Yu}$ and Roque for a detailed review of physical, virtual, and hybrid computational toys and kits that enable young children (ages 7 years old and under) to explore computational ideas and practices [44] and the literature review of Jung and Won for a systematic and thematic review on existing literature in robotics education using robotics kits (not social robots) for young children (Pre-K and kindergarten through 5th grade) [54]. Another valuable and interesting work is an online database available on the website https://robots-for-education.com in which someone can find a taxonomy of educational robotics [55].

In conclusion, the purpose of this article is not to advocate against an educational robot or robotic kit but indeed to inform the educational community so that to make informed decisions regarding the introduction of this kind of technology into the classroom. The detailed description of the characteristics of the robots and robotic kits was not within the scope of this article, but we hope this issue to be covered with a systematic literature review in another article.

\section{Competing Interests}

The author declares that he has no competing interests.

\section{$6 \quad$ Funding}

The author received no financial support for the research, authorship, and/or publication of this article. 


\section{$7 \quad$ References}

[1] Papadakis, S., Kalogiannakis, M., Orfanakis, V., \& Zaranis, N. (2017). The appropriateness of scratch and app inventor as educational environments for teaching introductory programming in primary and secondary education. International Journal of Web-Based Learning and Teaching Technologies (IJWLTT), 12(4), 58-77. https://doi.org/10.4018/ijwltt.2017100106

[2] Urlings, C. C., Coppens, K. M., \& Borghans, L. (2019). Measurement of Executive Functioning Using a Playful Robot in Kindergarten. Computers in the Schools, 36(4), 255-273. https://doi.org/10.1080/07380569.2019.1677436

[3] Chatzopoulos, A., Papoutsidakis, M., Kalogiannakis, M., \& Psycharis, S. (2019). Action Research Implementation in Developing an Open Source and Low-Cost Robotic Platform for STEM Education. International Journal of Computer Applications, 178(24), 33-46. https://doi.org/10.5120/ijca2019919039

[4] Duncan, C., Bell, T., \& Tanimoto, S. (2014). Should your 8-year-old learn coding? In Proceedings of the 9th Workshop in Primary and Secondary Computing Education (WiPSCE '14) (pp. 60-69), 05-07, Nov, Berlin, Germany. ACM. https://doi.org/10.1145/2670 $\underline{757.2670774}$

[5] Caballero-Gonzalez, Y. A., Muñoz-Repiso, A. G. V., \& García-Holgado, A. (2019). Learning computational thinking and social skills development in young children through problem solving with educational robotics. In Proceedings of the Seventh International Conference on Technological Ecosystems for Enhancing Multiculturality (pp. 19-23). ACM. https://doi.org/10.1145/3362789.3362874

[6] Nikolopoulou, K., \& Gialamas, V. (2015). Barriers to the integration of computers in early childhood settings: Teachers' perceptions. Education and Information Technologies, 20(2), 285-301. https://doi.org/10.1007/s10639-013-9281-9

[7] Papadakis, S., Vaiopoulou, J., Kalogiannakis, M., \& Stamovlasis, D. (2020). Developing and Exploring an Evaluation Tool for Educational Apps (ETEA) Targeting Kindergarten Children. Sustainability, 12(10), 4201. https://doi.org/10.3390/su12104201

[8] Sullivan, A., \& Bers, M. U. (2016). Robotics in the early childhood classroom: learning outcomes from an 8-week robotics curriculum in pre-kindergarten through second grade. International Journal of Technology and Design Education, 26(1), 3-20. https://doi.org/ $10.1007 / \mathrm{s} 10798-015-9304-5$

[9] Mondada, F., Bonani, M., Riedo, F., Briod, M., Pereyre, L., Rétornaz, P., \& Magnenat, S. (2017). Bringing robotics to formal education: The thymio open-source hardware robot. IEEE Robotics \& Automation Magazine, 24(1), 77-85. https://doi.org/10.1109/mra.2016. $\underline{2636372}$

[10] Papadakis, S., \& Kalogiannakis, M. (2019). Evaluating a course for teaching introductory programming with Scratch to pre-service kindergarten teachers. International Journal of Technology Enhanced Learning, 11(3), 231-246. https://doi.org/10.1504/ijtel.2019.100478

[11] Noh, J., \& Lee, J. (2020). Effects of robotics programming on the computational thinking and creativity of elementary school students. Educational Technology Research and Development, 68(1), 463-484. https://doi.org/10.1007/s11423-019-09708-w

[12] Di Lieto, M. C., Pecini, C., Castro, E., Inguaggiato, E., Cecchi, F., Dario, P., Cioni, G., \& Sgandurra, G. (2020). Empowering Executive Functions in 5-and 6-Year-Old Typically Developing Children Through Educational Robotics: An RCT Study. Frontiers in psychology, 10, 3084. https://doi.org/10.3389/fpsyg.2019.03084

[13] García-Valcárcel-Muñoz-Repiso, A., \& Caballero-González, Y. A. (2019). Robotics to develop computational thinking in early Childhood Education. Comunicar. Media Education Research Journal, 27(1). https://doi.org/10.3916/c59-2019-06 
[14] Piaget, J. (1970). Genetic epistemology. New York: W. W. Norton and Company.

[15] Papert, S. (1980). Mindstorms. New York: Basic Rooks.

[16] Anwar, S., Bascou, N. A., Menekse, M., \& Kardgar, A. (2019). A Systematic Review of Studies on Educational Robotics. Journal of Pre-College Engineering Education Research (J-PEER), 9(2), 2. https://doi.org/10.7771/2157-9288.1223

[17] Souza, I. M., Andrade, W. L., Sampaio, L. M., \& Araujo, A. L. S. O. (2018, October). A Systematic Review on the use of LEGO ${ }^{\circledR}$ Robotics in Education. In 2018 IEEE Frontiers in Education Conference (FIE) (pp. 1-9). IEEE. https://doi.org/10.1109/fie.2018.8658751

[18] Kim, C., Kim, D., Yuan, J., Hill, R. B., Doshi, P., \& Thai, C. N. (2015). Robotics to promote elementary education pre-service teachers' STEM engagement, learning, and teaching. Computers \& Education, 91, 14-31. https://doi.org/10.1016/j.compedu.2015.08.005

[19] Sullivan, A. A., Bers, M. U., \& Mihm, C. (2017). Imagining, playing, and coding with KIBO: using robotics to foster computational thinking in young children. Proceedings of the International Conference on Computational Thinking Education. Wanchai, Hong Kong.

[20] Dorouka, P., Papadakis, S., \& Kalogiannakis, M. (2020). Tablets and apps for promoting robotics, mathematics, STEM education and literacy in early childhood education. International Journal of Mobile Learning and Organisation, 14(2), 255-274. https://doi.org/10. 1504/ijmlo.2020.10026334

[21] Rose, S. (2019). Developing Children's Computational Thinking using Programming Games (Doctoral dissertation, Sheffield Hallam University).

[22] Eteokleous, N. (2019). Robotics and Programming Integration as Cognitive-Learning Tools. In Advanced Methodologies and Technologies in Artificial Intelligence, Computer Simulation, and Human-Computer Interaction (pp. 1085-1099). IGI Global. https://doi.org/10. 4018/978-1-5225-7368-5.ch079

[23] Benitti, F. B. V. (2012). Exploring the educational potential of robotics in schools: A systematic review. Computers \& Education, 58(3), 978-988. https://doi.org/10.1016/j. compedu.2011.10.006

[24] Komis, V., Romero, M., \& Misirli, A. (2016). A scenario-based approach for designing educational robotics activities for co-creative problem solving. In International Conference EduRobotics 2016 (pp. 158-169). Springer, Cham. https://doi.org/10.1007/978-3-31955553-9_12

[25] Komis, V., \& Misirli, A. (2016). The environments of educational robotics in Early Childhood Education: towards a didactical analysis. Educational Journal of the University of Patras UNESCO Chair, 3(2), 238-246.

[26] Chawla, K., Chiou, M., Sandes, A., \& Blikstein, P. (2013). Dr. Wagon: a 'stretchable' toolkit for tangible computer programming. In Proceedings of the 12th international conference on interaction design and children (pp. 561-564). New York, NY, USA. https://doi.org/10.1145/ 2485760.2485865

[27] Frei, P., Su, V., Mikhak, B., \& Ishii, H. (2000). Curlybot: designing a new class of computational toys. In Proceedings of the SIGCHI conference on Human factors in computing systems (pp. 129-136). https://doi.org/10.1145/332040.332416

[28] Wyeth,P, \& Wyeth, G. (2001). Electronic blocks: Tangible programming elements for preschoolers, in: Proc. Eighth IFIP TC13 Conf. Human-Computer Interact, 496-503.Lisbon, Portugal.

[29] Gordon, M., Rivera, E., Ackermann, E., \& Breazeal, C. (2015). Designing a relational social robot toolkit for preschool children to explore computational concepts. In Proceedings of the 14th International Conference on Interaction Design and Children (pp. 355-358). Medford, USA. ACM. https://doi.org/10.1145/2771839.2771915 
[30] Huijnen, C. A., Lexis, M. A., \& de Witte, L. P. (2016). Matching robot KASPAR to autism spectrum disorder (ASD) therapy and educational goals. International Journal of Social Robotics, 8(4), 445-455. https://doi.org/10.1007/s12369-016-0369-4

[31] Lücking, P., Rohlfing, K., Wrede, B., \& Schilling, M. (2016, September). Preschoolers' engagement in social interaction with an autonomous robotic system. In 2016 Joint IEEE International Conference on Development and Learning and Epigenetic Robotics (ICDL-EpiRob) (pp. 210-216). IEEE. https://doi.org/10.1109/devlrn.2016.7846821

[32] Misirli, A., \& Komis, V. (2014). Robotics and programming concepts in Early Childhood Education: A conceptual framework for designing educational scenarios. In Research on eLearning and ICT in Education (pp. 99-118). Springer, New York, NY. https://doi.org/10. 1007/978-1-4614-6501-0 8

[33] Patterson, S. (2016). Programming in the primary grades: beyond the hour of code. Rowman \& Littlefield.

[34] Anzoátegui, L. G. C., Pereira, M. I. A. R., \& Jarrín, M. D. C. S. (2017). Cubetto for preschoolers: Computer programming code to code. In 2017 International Symposium on Computers in Education (SIIE) (pp. 1-5), 9-11 November 2017, Lisbon, Portugal. IEEE. https://doi.org/10.1109/siie.2017.8259649

[35] Schley, C. (2017). Learning Toys and STEM Toys We Love. Available: https://thewirecutter.com/reviews/learning-toys-and-stem-toys-we-love/ [Accessed July. 18, 2020].

[36] Glezou, K. V. (2020). Fostering Computational Thinking and Creativity in Early Childhood Education: Play-Learn-Construct-Program-Collaborate. In Mobile Learning Applications in Early Childhood Education (pp. 324-347). IGI Global. https://doi.org/10.4018/978-1-79981486-3.ch016

[37] Riedo, F., Chevalier, M., Magnenat, S., \& Mondada, F. (2013). Thymio II, a robot that grows wiser with children. In 2013 IEEE Workshop on Advanced Robotics and its Social Impacts (pp. 187-193). IEEE. https://doi.org/10.1109/arso.2013.6705527

[38] Vitanza, A., Rossetti, P., Mondada, F., \& Trianni, V. (2019). Robot swarms as an educational tool: The Thymio's way. International Journal of Advanced Robotic Systems, 16(1), 1729881418825186. https://doi.org/10.1177/1729881418825186

[39] Heljakka, K., Ihamäki, P., Tuomi, P., \& Saarikoski, P. (2019). Gamified Coding: Toy Robots and Playful Learning in Early Education. In 2019 International Conference on Computational Science and Computational Intelligence (CSCI) (pp. 800-805). IEEE. https://doi.org/ $\underline{10.1109 / \mathrm{csci} 49370.2019 .00152}$

[40] Cardoso, I., \& Cardoso, I. (2005). Roamer Robot in Portugal. EuroLogo Warsaw.

[41] João-Monteiro, M., Cristóvão-Morgado, R., Cruz, M. G. B., \& Morgado, L. (2003). A robot in kindergarten. Eurologo 2003, pp.382-387, Coimbra, Portugal.

[42] Brauner, D. (2016). Code-A-Pillar. Available: https://www.perkinselearning.org/technology/posts/code-pillar [Accessed July. 18, 2020].

[43] Clarke-Midura, J., Lee, V. R., Shumway, J. F., \& Hamilton, M. M. (2019). The building blocks of coding: a comparison of early childhood coding toys. Information and Learning Sciences, 120, 7/8, 505-518. https://doi.org/10.1108/ils-06-2019-0059

[44] Yu, J., \& Roque, R. (2019). A review of computational toys and kits for young children. International Journal of Child-Computer Interaction. 21, 17-36. https://doi.org/10.1016/j. ijcci.2019.04.001

[45] Bertel, L. B., Brooks, E., \& Dau, S. (2019). Robot-Supported Inclusion and Learning: A Case Study on the KUBO Robot in Early Childhood Education. In Global Challenges in Assistive Technology: Research, Policy \& Practice (AAATE 2019), Vol. 31, No. 1. Bologna, Italy. 
[46] Moher, D., Shamseer, L., Clarke, M., Ghersi, D., Liberati, A., Petticrew, M., Shekelle, P., \& Stewart, L. A. (2015). Preferred reporting items for systematic review and meta-analysis protocols (PRISMA-P) 2015 statement. Systematic reviews, 4(1), 1. https://doi.org/10.1186/ 2046-4053-4-1

[47] Gialamas, V., \& Nikolopoulou, K. (2010). In-service and pre-service early childhood teachers' views and intentions about ICT use in early childhood settings: A comparative study. Computers \& Education, 55(1), 333-341. https://doi.org/10.1016/j.compedu.2010.01.019

[48] Kalogiannakis, M., Nirgianaki, G. M., \& Papadakis, S. (2018). Teaching magnetism to preschool children: The effectiveness of picture story reading. Early Childhood Education Journal, 46(5), 535-546. https://doi.org/10.1007/s10643-017-0884-4

[49] Dunphy, L. (2020). A Picture Book Pedagogy for Early Childhood Mathematics Education. In MacDonald, A., Danaia, L., \& Murphy, St. (Eds.) STEM Education Across the Learning Continuum (pp. 67-85). Springer, Singapore. https://doi.org/10.1007/978-981-15-2821-7 5

[50] Papadakis, S., Zaranis, N., \& Kalogiannakis, M. (2019). Parental involvement and attitudes towards young Greek children's mobile usage. International Journal of Child-Computer Interaction, 22, 100144. https://doi.org/10.1016/j.ijcci.2019.100144

[51] Kanaki, K., \& Kalogiannakis, M. (2018). Introducing fundamental object-oriented programming concepts in preschool education within the context of physical science courses, Education and Information Technologies, 23(6), 2673-2698. https://doi.org/10.1007/s10639018-9736-0

[52] Papadakis, S. (2020). Apps to Promote Computational Thinking Concepts and Coding Skills in Children of Preschool and Pre-Primary School Age. In Mobile Learning Applications in Early Childhood Education (pp. 101-121). IGI Global. https://doi.org/10.4018/978-1-79981486-3.ch006

[53] Papadakis, S., Kalogiannakis, M., \& Zaranis, N. (2018). The effectiveness of computer and tablet assisted intervention in early childhood students' understanding of numbers. An empirical study conducted in Greece. Education and Information Technologies, 23(5), 18491871. https://doi.org/10.1007/s10639-018-9693-7

[54] Jung, S. E., \& Won, E. S. (2018). Systematic review of research trends in robotics education for young children. Sustainability, 10(4), 905. https://doi.org/10.3390/su10040905

[55] Catlin, D., Kandlhofer, M., Cabibihan, J. J., Angel-Fernandez, J., Holmquist, S., \& Csizmadia, A. P. (2019). EduRobot taxonomy. In L. Daniela (ed.), Smart Learning with Educational Robotics (pp. 333-338). Springer, Cham. https://doi.org/10.1007/978-3-030-19913-5_15

\section{Author}

Dr. Stamatios Papadakis has been a postdoctoral researcher in Educational Technology, with emphasis on mobile learning, at the Department of Preschool Education at the University of Crete, Greece since 2016. His scientific and research interests include the study of mobile learning, especially on the use of smart mobile devices and their accompanying mobile applications (apps) in the use of Preschool and Primary Education, focusing on the development of Computational Thinking and students' understanding of numbers. Furthermore, he currently investigates how a STEM learning approach influences learning achievement through a context-aware mobile learning environment in the preschool classroom and to explain effects on preschoolers' learning outcome.

Article submitted 2020-06-26. Resubmitted 2020-08-05. Final acceptance 2020-08-06. Final version published as submitted by the authors. 